Viso - Cadernos de estética aplicada Revista eletrônica de estética

ISSN 1981-4062

No 18, jan-jun/2016

http://www.revistaviso.com.br/

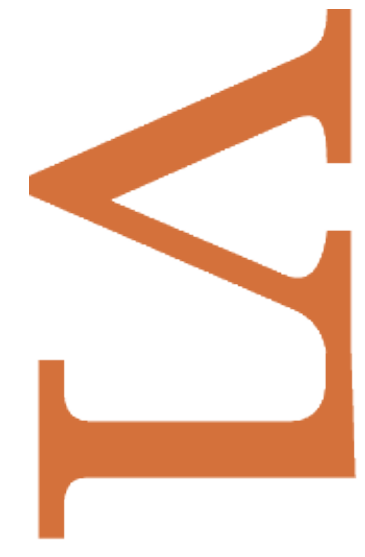

\title{
Memória, história e narração: $O$ céu sobre Berlim ou Wim Wenders, leitor de Benjamin
} Ernani Chaves 


\section{RESUMO}

Memória, história e narração: O Céu sobre Berlim ou Wim Wenders, leitor de Walter Benjamin

O objetivo deste artigo é analisar a referência Walter Benjamin que se encontra no filme de Wim Wenders, O céu sobre Berlim, mais conhecido no Brasil por seu título traduzido do francês, As asas do desejo. Três temas benjaminianos, o da memória, o da história e o da narração estão presentes no filme, reunidos por uma outra temática, ou melhor, pela presença das figuras de anjos, protagonistas da história. Procura-se compreender a presença de Benjamin, seja por meio das referências explícitas e implícitas feitas a ele ou a temas de sua obra no filme, como também por uma rápida reconstrução da importância de Benjamin nas discussões sobre as relações entre cinema e política na Alemanha a partir da década de 1960, coincidindo com os estudos de Wenders na Escola de Cinema de Munique.

Palavras-chave: história - memória - narração - cinema

\section{ABSTRACT}

Memory, History and Narration: The Sky over Berlin or Wim Wenders,

\section{Walter Benjamin's Reader}

The purpose of this article is to analyze the reference to Walter Benjamin in the Wim Wender's film, "The sky over Berlin", better known in Brazil for its title translated from French, "Wings of desire". Three of Benjamin's themes, memory, history and narration are present in the film, assembled by another theme, or better, by the presence of figures of angels, protagonists of the story. Looking for understand the presence of Benjamin, either through explicit and implicit references made of him or the themes of his work in the film, as also for a quick reconstruction of the importance of Benjamin in the discussions on the relationship between cinema and politics in Germany from the early 1960, coinciding with the Wenders Film School in Munich.

Keywords: history - memory - naration - cinema 
CHAVES, E. "Memória, história e narração: O Céu sobre Berlim ou Wim Wenders, leitor de Walter Benjamin". In: Viso: Cadernos de estética aplicada, v. X, n. 18 (jan-jun/2016), pp. 111-123.

DOI: 10.22409/1981-4062/v18i/221

Aprovado: 30.04.2016. Publicado: 03.07.2016.

(C) 2016 Ernani Chaves. Esse documento é distribuído nos termos da licença Creative Commons Atribuição-NãoComercial 4.0 Internacional (CC-BY-NC), que permite, exceto para fins comerciais, copiar e redistribuir o material em qualquer formato ou meio, bem como remixá-lo, transformá-lo ou criar a partir dele, desde que seja dado o devido crédito e indicada a licença sob a qual ele foi originalmente publicado.

Licença: http://creativecommons.org/licenses/by-nc/4.0/deed.pt BR

Accepted: 30.04.2016. Published: 03.07.2016.

(C) 2016 Ernani Chaves. This document is distributed under the terms of a Creative Commons Attribution-NonCommercial 4.0 International license (CC-BY-NC) which allows, except for commercial purposes, to copy and redistribute the material in any medium or format and to remix, transform, and build upon the material, provided the original work is properly cited and states its license.

License: http://creativecommons.org/licenses/by-nc/4.0/ 
Es war ein dunkles, unbekanntes Berlin, das sich im Gaslicht vor mir ausbreitete.

Era uma Berlim escura, desconhecida, que se estendia diante de mim, sob a luz do gás.

Walter Benjamin

Para Thomas Schirmer.

\section{Anjos descem à terra}

Há vinte e cinco anos, o cineasta alemão Wim Wenders recebia o prêmio de melhor diretor no Festival de Cannes com um filme estranhamente belo, mais conhecido pelo título francês - Les ailes du désir (As asas do desejo) - do que por seu título original Der Himmel über Berlin (O céu sobre Berlim). História escrita com um velho parceiro, o escritor, poeta, dramaturgo e ensaísta austríaco Peter Handke. Beleza estranha, por sua história inusitada, história de anjos que descem à terra e dos que resolvem se destituir do caráter angelical, isto é, da imortalidade, para viver as intermitências do coração humano. Beleza estranha acentuada pela oscilação na cor, ora em preto e branco, ora colorido, mudanças formais que pontuam, acompanham, ou ainda interrompem o andamento da história. Beleza estranha ainda, por situar a narrativa em vários planos temporais, entre passado e presente, reunidos por imagens de documentários, que mostram, não por acaso, a Alemanha da época do nazismo. Todos esses planos, repletos de ruínas - planos da memória, que implicam modos diferentes de narrar - são acolhidos, se reúnem, mas também se dispersam num mesmo lugar, num mesmo Schauplatz: uma cidade, não qualquer cidade, mas Berlim, uma cidade emblemática para a nossa memória recente, repleta de memórias de guerra, de destruição, Berlim como o centro irradiador da barbárie que assolou o mundo entre 1933 e 1945, Berlim como centro das disputas de poder durante a chamada "guerra fria", que culminou na divisão da cidade pelo famoso "muro".

Essa Berlim sombria, reduzida a um infinito amontoado de ruínas em 1945, nos faz frequentemente esquecer aquela outra Berlim, a cidade das grandes experimentações artísticas das primeiras décadas do século XX. Pouco lembramos da Berlim dos cabarés (imortalizada no cinema em tantos filmes, como no Anjo azul, com Marlene Dietrich, ou ainda em Cabaré, com Liza Minelli, para citar dois exemplos extremos), da cidade vermelha, revolucionária, a Berlim da "Liga Spartakus" de Karl Liebknecht e Rosa Luxemburgo, a Berlim dos anos 1920, os "anos loucos", a dos Expressionistas (que iam das artes plásticas ao cinema, dos "retratos de cidade" de Ernst Ludwig Kirchner à Metrópolis de Fritz Lang), a da Bauhaus, a de Brecht, a de Alfred Döblin (o autor de Berlin Alexanderplatz), a de Georg Simmel, Sigfried Kracauer, Franz Hessel e, em especial, aquela evocada por Walter Benjamin. Não que essas outras "Berlins" sejam romanticamente belas, idealizadas, ou que estejam livres do que há de sombrio e obscuro nas cidades modernas. Mas porque Berlim, mais do que qualquer outra cidade do Ocidente nos últimos cem anos, é o emblema dessa divisão, dessa Spaltung (palavra 
tão cara ao vocabulário freudiano) entre cultura e barbárie, memória e esquecimento, trauma e (im)possibilidade de elaboração, que marca nossa época, em qualquer lugar em que estejamos ou vivamos.

Quando Wim Wenders - já famoso internacionalmente com Paris, Texas, que havia ganhado em 1984 a Palma de Ouro, em Cannes ${ }^{1}$ - resolveu fazer um filme em Berlim, a cidade já se tornara, desde alguns anos, o seu "dormitório" e, aos poucos, ele, que nascera em Düsseldorf, começa a se sentir em casa vivendo em Berlim, "mesmo que esta cidade seja observada com os olhos de alguém que esteve muito tempo ausente". ${ }^{2}$ Esta declaração é duplamente importante, porque marca uma mudança radical na vida de Wenders, qual seja, seu retorno à Alemanha, depois da tentativa frustrante de fazer uma carreira em Hollywood. Retorno à pátria, mas não a qualquer lugar, retorno a uma cidade muito especial, um retorno a Berlim. Ele imaginou, incialmente, a história de alguém que retorna a uma cidade para redescobri-la - um pouco como Travis, a figura central de Paris, Texas, como o próprio Wenders afirma no mesmo texto que acabei de citar - e, neste processo, ele redescobre não apenas Berlim, mas também a Alemanha. A imagem de um "anjo" Ihe veio a partir da leitura recente das Elegias de Duíno, de Rainer Marie Rilke, do prazer em reconhecer que "tudo o que Rilke escreveu estava povoado de anjos", assim como a constatação talvez pueril demais de que um anjo podia tudo: "atravessar o muro, entrar nas casas pela janela, acompanhar as pessoas no metrô". Ou ainda do filme de Howard Hawks, Only Angels Have Wings, de 1933 (no Brasil se chamou Paraíso infernal), que sinaliza para a semelhança ancestral entre anjos e aviadores, seres alados, embora as asas desses últimos possam se desprender e cair. ${ }^{3}$

Wim Wenders completa o que ele próprio chama de "outra origem" do filme com uma confissão surpreendente, mas bastante esclarecedora. Ele nos lembra de uma das cenas ao final de Paris, Texas, quando a personagem de Natassja Kinski reencontra seu filho. Comentando esta cena, Wenders escreve:

Ele corre para sua mãe, ela o toma nos braços. Para mim, esta cena teve um efeito libertador: era o sentimento de que eu sabia que esta cena teria consequências nos meus próximos filmes, fossem elas quais fossem (A última tomada, quando Travis vai embora: do meu modo, deixei que ele desaparecesse e com ele se foram todas as figuras masculinas dos meus primeiros filmes. Agora, todas elas foram deixadas em um asilo, nos arredores de Paris, Texas). Tive então um forte desejo de escolher uma mulher como protagonista. ${ }^{4}$

Mas a ideia de fazer do anjo uma figura feminina foi substituída por outra, mais contundente: a de deixar que o anjo, como uma figura masculina, se decidisse a abandonar sua vida eterna pelo desejo despertado pela visão de uma mulher, de uma trapezista, de uma mulher que duplicava a figura angelical: não só porque "voava" no trapézio, mas também porque se apresentava no circo, adornada com asas. Embora Marion (papel da inesquecível Solveig Donmartin, que morreu precocemente, em 2007, aos 48 anos de idade) não fosse um anjo como Damiel (Bruno Ganz), ela parecia 
mostrar a ele que nós também, os simples mortais, desejamos ser anjos, desejamos voar, em última instância, também desejamos a imortalidade. A decisão de Wim Wenders só faz sentido, pelo menos para mim, de um ponto de vista psicanalítico, mais especialmente na confluência entre Freud e Lacan: não há humano possível sem o toque do desejo. Ou ainda, se recuarmos mais ainda em direção às raízes do nosso modo de pensar, reencontramos a relação entre Eros e desejo de imortalidade no Banquete, de Platão. Assim, pode-se dizer que a figura de Marion também é protagonista, na medida em que, sem ela, a conversão ao humano por parte de Damiel não seria possível. É por ela que ele decide enfrentar as vicissitudes da vida dos mortais. Eros, desejo alado, uma imagem tão antiga quanto aquela evocada no Fedro, outro diálogo de Platão. Eros, o que liga, o que enlaça e, na visão psicanalítica à qual me referi, o que nos acopla também, como sujeitos, ao social, à história, à cultura. Assim, Damiel precisa aprender duas coisas ao mesmo tempo: que ser humano não é apenas sentir o gosto das coisas, o calor ou o frio, amar e desejar ou ainda vestir roupas compradas numa Zweite Hand (literalmente "segunda mão"; aludo aqui ao nome de uma grande cadeia de lojas de roupas usadas, existente em toda Alemanha), mas também falar uma língua, professar hábitos e valores que se pretendem comuns, partilhar crenças, sentimentos, afetos.

Mas, em outro texto evocador das origens do filme, Wenders amplia as suas fontes:

É-me ainda, mesmo agora, difícil saber, como surgiu a ideia de povoar com anjos minha história em Berlim. Ela me chegou de muitas fontes ao mesmo tempo. Sobretudo, das Elegias de Duíno, de Rilke. Mas já estavam presentes [em mim], há muito tempo, as imagens de Paul Klee. O Anjo da história, de Walter Benjamin. ${ }^{5}$

Referência explícita, como vimos, tanto aos anjos de Klee, como à alegoria do "anjo da história", nas "Teses" sobre o conceito de história, de Walter Benjamin, que, por sua vez, faz alusão a um dos anjos de Klee. A referência a Benjamin não é fortuita, ocasional, estando diretamente relacionada à história da recepção de seu pensamento na Alemanha, em especial a partir do movimento estudantil de 1968, quando ele se torna o emblema de uma esquerda não dogmática. Por outro lado, Wenders pertence à segunda geração dos cineastas que passaram à história do cinema como fazendo parte do famoso movimento intitulado de "O novo/jovem cinema alemão", uma geração que, ao contrário da primeira, que aprendera na "prática", frequentou uma escola de cinema. No caso de Wenders, a recém-criada Faculdade de Televisão e Cinema de Munique, na qual concluiu seus estudos em 1970, na primeira turma ${ }^{6}$ Antes, ele já tinha abandonado os cursos de Medicina e o de Filosofia. Pode-se dizer então que tanto no curso de Filosofia quanto no de Cinema, Wenders teve contato direto com o pensamento de Benjamin, cujo texto sobre a reprodutibilidade técnica das obras de arte, no qual o papel do cinema é absolutamente fundamental, havia se transformado em leitura obrigatória. Wenders vivenciou, portanto, durante sua formação profissional, um momento muito especial da recepção do pensamento de Walter Benjamin, reivindicado como um dos ícones do movimento estudantil da época. ${ }^{7}$ Por outras vias, Benjamin fortalecia a crítica do "Manifesto de Oberhausen" contra o "cinema do papai". ${ }^{8}$ Poderíamos dizer que este 
último dava continuidade ao processo de "estetização da política" que Benjamin havia diagnosticado nos filmes de propaganda nazista dos anos 1930, deixando claro assim que entre a produção cinematográfica alemã do pós-guerra e os filmes da época do nazismo não havia uma ruptura completa. Era preciso, portanto, que o cinema alemão assumisse uma posição crítica diante do passado nazista, que ele também pudesse ser um veículo de "elaboração do passado", que ele fizesse parte do "trabalho de luto" que se impunha à sociedade alemã, uma sociedade que os psicanalistas Alexander e Margarete Mitscherlich, em 1967, haviam diagnosticado como portadora de uma "incapacidade para o luto". O livro do casal Mitscherlich fazia eco aos artigos importantes de Theodor Adorno acerca da necessidade que a sociedade alemã tinha de se apropriar criticamente do passado nazista, para poder superá-lo, no sentido psicanalítico de "elaboração do passado", enfatizando, entretanto, a ligação entre o individual e o social, entre o psíquico e a história.

Os filmes de Wim Wenders dos anos 1970 falam o tempo todo disso, eles são filmes políticos, mas num sentido muito especial, uma vez que, como assinala Buchka ${ }^{10}$, a "superficial ausência de política" neles presente revela, ao contrário do que se poderia pensar de imediato, "a justificativa para o processo que ele, com seus filmes, lança contra as relações políticas" existentes à época. Relembrando seu período como estudante na Escola de Cinema de Munique, Wenders articulou de modo bem claro a experiência de sua geração com a política, na esteira do maio de 1968: "De 1967 a 1970, fui aluno da Faculdade de Cinema de Munique. Era a época da revolução; recusávamos os professores e nós mesmos definíamos o currículo. Ainda por cima éramos a primeira turma: isso nos fazia imortais e sem nós a escola não existiria". ${ }^{11}$ Gostaria de justificar a ideia de que o cinema de Wenders tem uma preocupação de ordem política, que se relaciona diretamente com o problema dos alemães com o passado nazista, a partir de uma breve abordagem do nexo entre memória, história e narração em Der Himmel über Berlin.

\section{Angelus Novus}

Os anjos de Wim Wenders encontram morada e refúgio na Biblioteca Municipal de Berlim Ocidental, inaugurada depois da construção do "Muro". A relação entre os anjos e o espaço da biblioteca já nos coloca no interior do tema da memória. Uma biblioteca (literalmente, "depósito de livros") sempre pressupõe funções culturais e historicamente ligadas à memória: guarda, conversação, preservação e difusão, partilha. Uma biblioteca é um lugar onde experiências se cruzam e onde passado e presente se interpenetram. A primeira sequência na biblioteca descrita por Wenders e Handke nos mostra um movimento da câmera que capta, inicialmente e a partir do teto, a ampla sala do andar superior, mostrando os livros nas estantes e diversos leitores. Aparece um anjo feminino, ao lado de uma estudante de medicina e logo depois Damiel e Cassiel, que passam por ela e em seguida se separam. Wenders e Handke anotam o seguinte: "Cassiel 
permanece parado em pé, fecha os olhos e ouve o coro das vozes que preenchem a biblioteca como uma catedral". ${ }^{12}$ A relação entre biblioteca e catedral é, de fato, fortalecida pelo "coro das vozes" que se ouve, afirmando o lugar sagrado da biblioteca, uma sacralidade certamente vinculada ao papel que ela representa no plano da conservação e da difusão de uma cultura. Associada à catedral, ao plano do sagrado, a biblioteca ganha uma "aura", ideia que a atitude dos dois anjos de olhos fechados, com a cabeça para o alto (Cassiel) ou levemente inclinada (Damiel) só fazem reforçar. Essa imagem aurática, entretanto, vai ser logo em seguida questionada e, no limite, desfeita. Este processo, a meu ver, está inteiramente ligado à presença do pensamento de Benjamin no filme.

O primeiro questionamento aparece logo em seguida, quando ouvimos a voz do segundo leitor focalizado no filme. Ele diz:

Em 1921, Walter Benjamin comprou o Angelus Novus, uma aquarela de Paul Klee. Até sua fuga para Paris, em junho de 1940, o quadro ficou na parede dos seus diversos escritórios. Em seu último escrito, Sobre o conceito de história (1940), ele interpretou a imagem como alegoria do olhar para trás em direção à História". ${ }^{13}$

Esta referência ao quadro de Klee e ao último texto de Benjamin inicia esse processo de "desauratização" da biblioteca comparada a uma catedral. Inicia o processo de questionamento do poder de conservação e difusão da memória. A descrição que Benjamin faz do quadro de Klee, uma das mais conhecidas e comentadas de sua obra é, de início, a seguinte: "Nele está representado um anjo, que parece estar a ponto de afastar-se de algo em que crava o seu olhar. Seus olhos estão arregalados, sua boca está aberta e suas asas estão estiradas. O anjo da história tem de parecer assim". ${ }^{14}$ Benjamin construiu uma verdadeira "angeologia", mas sua presença na obra de Benjamin, como bem mostrou Jeanne-Marie Gagnebin, nos fala muito mais de "evasão e fuga", de tal modo que esta presença não é nem apaziguadora, nem consoladora, mostrando-se muito mais como angustiante e ameaçadora. ${ }^{15}$ Evasivos e insistentes, os anjos benjaminianos podem ser, ao mesmo tempo, uma fulguração entusiasmante e apaixonada e um desvanecimento de qualquer ilusão de perenidade, fixidez, verdade. São, ao mesmo tempo, "fulgurantes e efêmeros". Não são anjos da guarda; podendo ser, por exemplo, muito mais anunciadores da morte.

Tal como o Angelus Novus de Klee, o Anjo da história de Benjamin não possui uma bela aparência, ao contrário, seu rosto está muito mais próximo da deformação e da feiura. Ele não é "angelical" no sentido da representação mais comum que temos dos anjos. A descrição de Benjamin continua: "Ele tem seu rosto voltado para o passado. Onde diante de nós aparece uma cadeia de acontecimentos, ele enxerga uma única catástrofe, que sem cessar amontoa escombros sobre escombros e os arremessa aos seus pés". Ora, o que é o passado aqui, o que o constitui, qual passado é objeto do olhar desse anjo? Para Benjamin, o passado não é uma cadeia cronológica de fatos, uma sucessão entre causas e efeitos. Ao contrário, é uma "única catástrofe", um amontoado de escombros 
espalhados aos pés do anjo. Este, por princípio, nada pode fazer, pois é absolutamente impotente para evitar a catástrofe, um anjo, portanto, sem poder de proteção, embora ele o quisesse: "Ele bem gostaria de demorar-se, acordar os mortos e juntar os destroços". $\mathrm{O}$ que o impede, o que mina as suas forças?

Mas do paraíso sopra uma tempestade que se emaranha em suas asas e é tão forte que o anjo não mais pode fechá-las. Esta tempestade o impele irresistivelmente para 0 futuro, ao qual volta as costas, enquanto o amontoado de escombros diante dele cresce até o céu. O que nós chamamos de progresso, é essa tempestade.

O anjo sucumbe à tempestade que vem do paraíso, de um paraíso que também contradiz nossa ideia de paraíso. A tempestade, o que nós chamamos de "progresso", insiste em virar o nosso rosto para as promessas do futuro, fazendo-nos virar as costas para o passado. Numa palavra, o progresso, a "crença no progresso" dirá Benjamin em outra passagem das "Teses", significa, na nossa época, o esquecimento do passado e nos coage a construir uma memória que visa sempre o futuro, uma paradoxal memória sem passado. Uma memória que precisa ignorar o horror que lhe causam os escombros, as ruínas, em última instância, a fragilidade humana e o perecimento, a morte.

Ao contrário da interpretação de Jean-Michel Palmier, que enfatiza, seguindo as próprias indicações de Wenders, como vimos acima, a presença dos anjos de Rilke ${ }^{16}$, afirmando assim que o olhar dos anjos no filme é sempre de "ternura e amor", insisto em assinalar o elemento contrário: nem tanto "ternura e amor" e bem mais impotência e malestar. Com isso, me parece, o elemento político do filme pode se apresentar com mais evidência. Peter Falk, o conhecido ator americano, o detetive Columbo do seriado televiso, que interpreta a si mesmo no filme e que também foi um anjo que preferiu a vida humana, está em Berlim para rodar um filme baseado na Segunda Guerra Mundial. Esta é a oportunidade para Wenders acentuar, por meio das sucessivas imagens de escombros, de ruínas de Berlim após os bombardeios na Segunda Guerra, essa imagem do passado que o Anjo benjaminiano, na sua impotência, pode apenas contemplar. Assim como o trabalho do historiador materialista segundo Benjamin era o de construir o passado a partir desses escombros, de tal modo que outras vozes, outras narrativas, a "tradição dos oprimidos", como ele mesmo diz, pudessem vir à tona e adquirir direito de cidadania, Wim Wenders (e não apenas ele, evidentemente, porque esta é uma posição comum aos cineastas do "novo cinema alemão") toma para si a tarefa de não temer os escombros, a tarefa de enfrentar os fantasmas que assombraram a sua geração. Em outro texto de suas memórias, Wenders lembra que nasceu em 1945 e que durante sua infância na região do Reno costumava brincar entre os escombros. É essa história em escombros, em ruínas, que precisava ser contada nas escolas primárias da Alemanha, para que o passado pudesse ser elaborado, não para ser esquecido evidentemente, mas para ser incorporado à história do país e de cada um e, assim, evitar sua repetição. 


\title{
Homero (Curt Bois) ou da (im)possibilidade da narração.
}

O segundo elemento do filme que colabora com o processo de "desauratização" da memória como plena potência de conservação e transmissão é a figura de "Homero", representada pelo ator Curt Bois (1901-1991), cuja vida e carreira é muito representativa dentro da história do cinema alemão. Durante a Segunda Guerra, ele se exilou nos Estados Unidos e, em 1942, fez parte do clássico Casablanca. Depois da guerra ele voltou para a Alemanha e seu papel no filme de Wenders foi sua última performance. A propósito dele e de sua personagem no filme, escreveu Wenders:

\begin{abstract}
Os papéis de Curt Bois e de Peter Falk foram introduzidos muito depois, quando as filmagens já tinham começado. Bruno e Otto tinham me apresentado Curt Bois (em 1983 eles haviam rodado um documentário com ele e Bernhard Minett: Memória). Numa versão muito antiga, que eu contara a Peter Handke, havia a figura de um velho arcanjo, que mora na biblioteca. Peter não sabia como dar continuidade a esta ideia, mas diante de sua escrivaninha pendia, na parede, uma reprodução do Homero, de Rembrandt: um velho está sentado, ele fala - mas, para quem? Originalmente, no quadro de Rembrandt, para seus discípulos, mas o quadro foi cortado em duas metades e o narrador [der Erzähler], separado de seus ouvintes, de tal modo que ele fala sozinho. Peter gostava muito desse quadro e transformou minha ideia do arcanjo na do poeta imortal. De minha parte, não sabia como deveria integrar Homero no meu roteiro. Enfim, decidimos que Homero vive na biblioteca e que os diálogos de Peter são sua voz interior. Curt Bois não era nem anjo, nem humano, mas ambos ao mesmo tempo, pois ele era tão antigo quanto o cinema. ${ }^{17}$
\end{abstract}

A gênese da figura de "Homero" contada por Wenders é extremamente interessante, pois marca a passagem da ideia inicial - a de um Arcanjo, os "mensageiros celestiais" na tradição judaica - para a de um narrador que não possui mais ouvintes, a partir da leitura do quadro de Rembrandt. Dessa mistura paradoxal entre um "mensageiro" e um "narrador" cuja mensagem já não encontra nenhum ouvinte, nasce a figura fundamental de Curt Bois no filme. Novamente estamos diante de um tema benjaminiano igualmente decisivo: a perda da capacidade narrar, tal como outro ensaio famoso de Benjamin, $O$ narrador, de 1936, tematiza.

Como no início dos poemas homéricos, a figura de Homero aparece no filme, pela primeira vez, invocando as musas da narração, invocando uma época na qual a memória estava relacionada às narrativas orais. Novo paradoxo, na releitura que Wenders faz de Homero: enquanto o poeta grego ganha imortalidade ao reunir as diversas narrativas da tradição oral para escrever os seus poemas - a escrita agora como tentativa de fixar uma memória que poderia ser facilmente esquecida - o Homero de Wenders lamenta exatamente o contrário, ou seja, a transformação de seus ouvintes em leitores. Ouvimos então Homero dizer: "Meus ouvintes, com o tempo, se tornaram leitores e não se sentam mais em círculo, mas apenas sobre si mesmos e um nada sabe do outro. ${ }^{18}$ Entretanto, as musas da narração não lhe deixam em paz e mesmo "velho" e com a "voz alquebrada", a 
narração flui, se eleva, do mais profundo, e "a boca facilmente aberta a repete, tão forte, incansavelmente, como uma liturgia, durante a qual ninguém precisa guardar segredo, assim como palavras e frases são uma coisa só".

A perda da capacidade de narrar concomitante à perda da experiência no seu sentido forte, ou seja, como Erfahrung, experiência social, coletiva, historicamente construída e partilhada, em oposição à vivência, Erlebnis, particular e individual, é um dos temas do ensaio de Benjamin sobre a narração. No filme, a figura de Homero parece, em princípio, referendar o diagnóstico de Benjamin, na medida em que o arcanjo mensageiro não tem mais ouvintes. Seu único ouvinte - novo paradoxo - será Cassiel, o anjo que, justamente, não deseja ainda ser humano. É assim que, um pouco depois, Homero narra a Cassiel a história da Potsdamer Platz que, na época do filme, era um enorme terreno baldio, uma "terra de ninguém", como se costumava dizer, assombrada pelo Muro que dividia Berlim às proximidades da Biblioteca Municipal, da Filarmônica e da Nova Galeria Nacional. Uma história cindida pela ascensão do nazismo. Wenders, neste momento, toma para si uma leitura do ensaio de Benjamin plena de melancolia, pois a narração e o narrador parecem mesmo não mais encontrar sentido para sua existência. Se no ensaio de Benjamin são as condições próprias à sociedade capitalista que decretam que "a arte de narrar caminha para o fim"19, o filme de Wenders poderia acrescentar que estas condições adversas chegaram a seu ápice com o nazismo, com as bandeiras desenhadas com as suásticas que passam a ornamentar a Potsdamer Platz. Não por acaso, a segunda aparição de Homero na biblioteca é entrecortada por imagens dos horrores da Segunda Guerra. E se a musa da narração ou ainda o "Anjo da narração" [der Engel der Erzählung], explicitamente referido por Homero ${ }^{20}$ ainda é capaz de falar pela sua boca, ele, de fato, só possui um único ouvinte, alguém que, por ser anjo, não pode dar continuidade à cadeia de transmissão. No limite, ele não tem, de fato, nenhum ouvinte. Os regimes totalitários também se constituem à custa da invenção de uma linguagem igualmente totalitária, ou seja, aquela que pretende exterminar toda forma de expressão que não seja a sua, uma "novilíngua" ${ }^{11}$ permeada por "eufemismos, cinismo e covardia". ${ }^{22}$ Para isso, é também necessário exterminar o velho narrador que contava suas histórias para ouvintes sentados em círculo, à sua volta.

\footnotetext{
* Ernani Chaves é professor titular do Departamento de Filosofia da UFPA.

${ }^{1}$ Até então, a fama de Wim Wenders se resumia, pelo menos no Brasil, aos frequentadores dos chamados circuitos dos "cinemas de arte" ou ainda dos "cineclubes". Em Belém, Wim Wenders chegou ainda nos anos 1970, pelas mãos da Casa de Estudos Germânicos da UFPA. Lembro ainda, como estudante, do meu entusiasmo ao assistir $O$ medo do goleiro diante do pênalti, filme de Wenders de 1972.

${ }^{2}$ WENDERS, W. Die Logik der Bilder. Essays und Gespräche. Frankfurt: Verlag der Autoren, 1988, p. 133.

${ }^{3}$ Ibidem, p. 134. No número de junho de 1971, na revista Filmkritik, da qual Wenders foi crítico de
} 
cinema durante alguns anos, aparece a crítica a dois filmes sobre aviadores, um deles o de Hawks, acima referido. O outro, Furtchlosen Flieger (literalmente, "Aviadores indomáveis"), dirigido pelos alemães Veith von Fürstenberg e Martin Müller. WENDERS, W. Emotions Pictures. Essays und Filmkritiken. Frankfurt: Verlag der Autoren, 1988, p. 99.

${ }^{4}$ Os filmes anteriores de Wim Wenders são quase todos protagonizados por figuras masculinas. O clímax dessa preferência aparece em Im Lauf der Zeit (No decorrer do tempo), de 1976, uma espécie de road movie no interior da Alemanha. "Bruno" e "Robert", vividos por Rüdiger Vögler e Hanns Zischler (dois atores emblemáticos dos primeiros filmes de Wenders), representam segundo o próprio Wenders (Die Logik der Bilder. Op. cit., p. 23) um modo de narrar uma história entre homens, sem o "recalque" (Verdrängung, escreve Wenders, o que remete, explicitamente, ao conceito psicanalítico de "recalque") presente nos filmes de Hollywood. Uma história, completa ele, "da ausência de mulheres, que é, ao mesmo tempo, a história de uma nostalgia, como se elas estivessem presentes".

${ }^{5}$ WENDERS, W. Die Logik der Bilder. Op. cit., p. 97.

${ }^{6}$ BUCHKA, P. Augen kann man nicht kaufen. Wim Wenders und seine Filme. Frankfurt: Fischer, 1985, p. 7.

7 Em seu artigo sobre as "Teses" de Benjamin acerca do conceito de História, publicado inicialmente em 1967, Heinz-Dieter Kittsteiner assim se referiu, alguns anos depois, lembrando o contexto político da época: "Este artigo não foi o resultado de uma maçante preocupação filológica, mas a tentativa rapidamente esboçada, de contribuir para uma articulação entre as 'Teses sobre o conceito de História' e uma experiência histórica: ele não é uma contribuição à pesquisa erudita sobre Benjamin, mas um documento da história do movimento estudantil". KITTSTEINER, H.-D. "Die 'geschichtsphilosophischen Thesen'”. In: BULTHAUP, P. (org.) Materialien zu Benjamins Thesen 'Über den Begriff der Geschichte'. Beiträge und Interpretationen. Frankfurt: Suhrkamp, 1975 [1960], p. 39.

${ }^{8}$ Em 28 de fevereiro de 1962, durante a realização do Festival Internacional de Curta Metragem, na cidade de Oberhausen, 26 cineastas alemães presentes, dentre os quais se destacava Alexander Kluge, assinaram o famoso "Manifesto de Oberhausen", ponto de partida do chamado "Novo cinema alemão", que termina assim: "O antigo filme está morto. Nós acreditamos no novo". Esse "filme antigo" era chamado, genérica e ironicamente, de "cinema do papai". A este respeito, Adorno escreveu: "O abominável do cinema do papai é a infantilidade, a regressão industrialmente promovida". ADORNO, T. W. "Notas sobre o filme". In: COHN, G. (org.). Theodor W. Adorno. São Paulo: Ática, 1986 [1967], p. 100.

${ }^{9}$ ADORNO, T. W. "O que significa elaborar o passado". In: Educação e emancipação. São Paulo: Paz e Terra, 1995 [1960]; CHAVES, E. "O que está em jogo na 'elaboração' do passado? O 'teatro da memória' após Auschwitz”. In: PUCCI, B.; LASTÓRIA, L. A; COSTA, B. C. G. da (orgs.) Tecnologia, cultura e formação...ainda Auschwitz. São Paulo: Cortez Editora, 2003; GAGNEBIN, J.M. "O que significa elaborar o passado?". In: PUCCI, B.; LASTÓRIA, L. A; COSTA, B. C. G. da (orgs.) Tecnologia, cultura e formação...ainda Auschwitz. São Paulo: Cortez Editora, 2003.

${ }^{10}$ BUCHKA, P. Op. cit., p. 10.

11 WENDERS, W. Die Logik der Bilder. Op. cit., p. 111.

${ }^{12}$ WENDERS, W.; HANDKE, P. Der Himmel über Berlin. Ein Filmbuch. Frankfurt: Suhrkamp, 1990, p. 23. Para estas referências, remeto ao roteiro do filme, publicado em 1990. A versão brasileira do filme é bastante precária quanto à tradução, a qual em inúmeros momentos é imprecisa, em outros é equivocada e algumas vezes, pelo tamanho do texto que é falado, nem existe tradução.

${ }^{13}$ Ibidem. Esta é uma das passagens do filme que não foi traduzida na cópia brasileira, escapando inteiramente ao espectador que não sabe alemão. 
${ }^{14}$ Cito a partir da tradução de Jeanne-Marie Gagnebin e Marcos Lutz Müller: BENJAMIN, W. "Sobre o conceito de História". Tradução de Jeanne-Marie Gagnebin e Marcos Lutz Müller. In: LÖWY, M. Walter Benjamin: aviso de incêndio. Uma leitura das teses "Sobre o conceito de história”. São Paulo: Boitempo Editorial, 2005 [1940], p. 87.

${ }^{15}$ GAGNEBIN, J.-M. "O hino, a brisa e a tempestade: Dos anjos em Walter Benjamin". In: Sete aulas sobre linguagem, memória e história. Rio de Janeiro: Imago, 2005 [1996], p. 122.

${ }^{16}$ PALMIER, J.-M. "Les anges, Berlin, les ruines et la mémoire. Variations sur Les Ailes du désir de Wim Wenders”. In: Retour à Berlin. Paris: Payot, 1989, p. 286.

${ }^{17}$ WENDERS, W. Die Logik der Bilder. Op. cit., p. 137.

${ }^{18}$ WENDERS, W.; HANDKE, P. Op. cit., p. 30. Homero, o poeta grego, tinha sido também um rapsodo, ou seja, aquele que, de cidade em cidade, narrava os acontecimentos que, posteriormente, se tornaram a matéria-prima da llíada e da Odisséia. É como se o Homero do filme fosse esse Homero raposdo e não ainda o poeta que se tornou famoso pelos seus dois poemas épicos.

${ }^{19}$ BENJAMIN, W. "O narrador". Tradução de Sérgio Paulo Rouanet. In: Obras escolhidas, v. 1. São Paulo: Brasiliense, 1994 [1936], p. 197.

${ }^{20}$ WENDERS, W.; HANDKE, P. Op. cit., p. 60.

${ }^{21}$ KLEMPERER, V. Os diários de Victor Klemperer: testemunhos clandestinos de um judeu na Alemanha nazista, 1933-1945. São Paulo: Companhia das Letras, 1999.

22 SELIGMANN-SILVA, M. O local da diferença: ensaios sobre memória, arte, literatura e tradução. São Paulo: Editora 34, 2005, p. 148. 